\title{
MARKETING DIGITAL EM TEMPOS DE CRISE
}

\author{
DIGITAL MARKETING IN CRISIS TIME
}

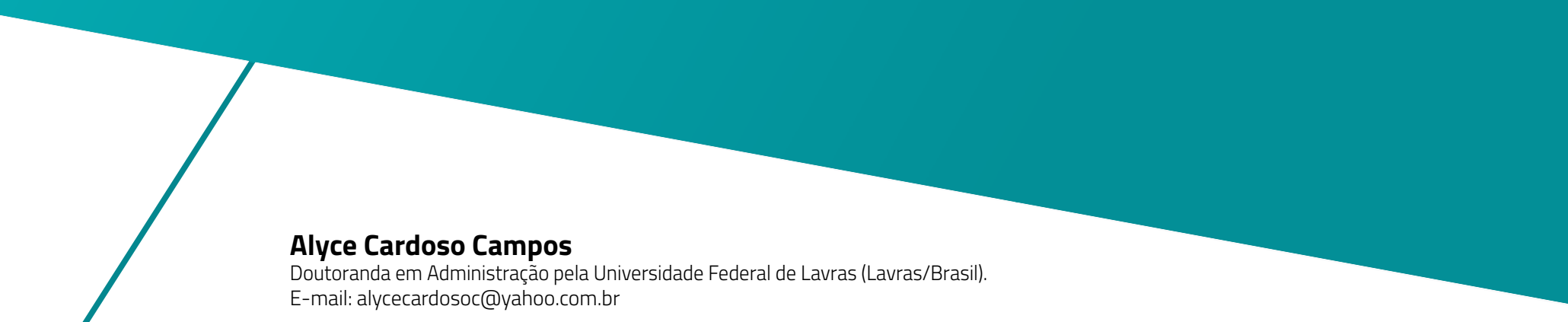

\section{Daniel Carvalho de Rezende}

Doutor em Ciências Sociais em Desenvolvimento, Agricultura e Sociedade pela Universidade Federal Rural do Rio de Janeiro (Seropédica/Brasil). Professor na Universidade Federal de Lavras (Lavras/Brasil).

E-mail: rezendedc@gmail.com

\section{Paulo Henrique Montagnana Vicente Leme}

Doutor em Administração pela Universidade Federal de Lavras (Lavras/Brasil).

Professor na Universidade Federal de Lavras (Lavras/Brasil).

E-mail: paulo.leme@ufla.br

\section{Mozar José de Brito}

Doutor em Administração pela Universidade de São Paulo (São Paulo/Brasil).

Professor na Universidade Federal de Lavras (Lavras/Brasil).

E-mail: mozarbrito@gmail.com

\section{Luiz Marcelo Antonialli}

Doutor em Administração pela Universidade de São Paulo (São Paulo/Brasil).

Professor na Universidade Federal de Lavras (Lavras/Brasil).

E-mail: Imantonialli@gmail.com 


\section{RESUMO}

A crise pode atingir uma organização por inúmeros motivos, dentre estes, por mudanças que ocorrem no mercado, na tecnologia, na concorrência ou até mesmo por uma pandemia vivida atualmente. Com isso, é necessário encontrar saídas para que seja possível contornar a situação e continuar atuando no mercado. Este artigo tem como objetivo analisar quais são as estratégias de marketing digital adotadas por organizações em diferentes situações de crise, inclusive a pandemia de Covid-19. Para isso, foi realizada uma revisão integrativa de artigos publicados nas bases Web of Science, Scopus, SPELL e SciELO. Os resultados mostram que diversas estratégias no meio digital são capazes de colaborar com os desafios que as organizações enfrentam com a globalização, como investir nos seus sites, atuar nas suas mídias sociais com conteúdo e campanhas, aplicativos, assistentes virtuais, publicidade e outros. Um framework de pesquisa foi criado com o objetivo de sintetizar as descobertas desta revisão integrativa. Organizações de diversos setores podem se espelhar nessas estratégias para lidar com a crise que enfrentam ou até mesmo aderi-las para que não sejam atingidas por adversidades inesperadas, resultando em perda de espaço ou até mesmo em sua retirada do mercado.

Palavras-chave: Estratégias digitais. Crises. Revisão integrativa da literatura.

\section{ABSTRACT}

The crisis can affect an organization for many reasons, including changes that occur in the market, technology, competition or even a pandemic currently experienced. With this, it is necessary to find solutions so that it is possible to work around the situation and continue operating in the market. This article aims to analyze what are the digital marketing strategies adopted by organizations in different crisis situations, including the Covid-19 pandemic. For this purpose, an integrative review of articles published in the Web of Science, Scopus, SPELL and SciELO databases was carried out. The results show that several strategies in the digital environment are capable of collaborating with the challenges that organizations face with globalization, such as investing in their websites, acting on their social media with content and campaigns, applications, virtual assistants, advertising and others. A research framework was created with the aim of synthesizing the findings of this integrative review. Organizations from different sectors can mirror these strategies to deal with the crisis they face or even join them so that they are not hit by unexpected adversities, resulting in loss of space or even their withdrawal from the market.

Keywords: Digital strategies. Crisis. Integrative literature review. 


\section{INTRODUÇÃO}

A Internet obteve um elevado crescimento, resultante de 50 anos de evolução, surgindo novos repertórios culturais e se tornando um sistema extraordinariamente complexo (BUSCA; BERTRANDIAS, 2020) ao permitir múltiplas finalidades (CARNIELLO; SANTOS; OLIVEIRA, 2011). Disponivel para todas as idades, a internet transfere a sociedade contemporânea para um mundo virtual. Os recursos tecnológicos permitiram evoluções que levaram a uma fácil acessibilidade dos consumidores digitais. Essa realidade exige que empresas estejam preparadas para as atuais e futuras mudanças no ambiente online, buscando novas maneiras de despertar desejo. O mundo está se deparando com o rápido avanço tecnológico e as organizações precisam encontrar maneiras para que consigam se sobressair no mercado. Com isso, buscam diferentes mecanismos para motivar os usuários a consumir seus produtos ou serviços (PÉREZFABARA; CHARRO, 2017).

Um número cada vez maior de empresas está buscando entrar para o mundo digital com o objetivo de ganhar visibilidade em seu mercado existente e também para conquistar novos mercados. Atualmente, em 2020, mesmo as pequenas empresas já buscam marcar presença na internet (CARPIO et al., 2020). Como a maioria das pessoas está envolvida na era digital, investir nesse meio se tornou a maneira mais eficiente de uma empresa alcançar clientes em potencial (KANNAN; LI, 2017) e também se aproximar de seu público de interesse através das possibilidades digitais (MACHADO, 2016).

A internet afetou a maneira como as pessoas vivem e modificou completamente a experiência humana. Ela é usada por diversos motivos, dentre estes, como forma de mídia, para assistir programas de televisão ou diversos outros conteúdos de entretenimento, para encontrar informações, comprar ou vender produtos ou serviços, procurar e contatar amigos, entre diversos outros (MARTíNEZ-LÓPEZ et al., 2015). A internet, enquanto tecnologia, está intimamente ligada também ao crescimento do uso dos dispositivos móveis. Uma mudança importante que deve ser considerada é o uso do smartphone pela maioria da população. Um uso que consome muitas horas do dia dos indivíduos para diferentes fins. Ele superou o uso de telefones fixos e permitiu novas tendências de marketing digital (PÉREZ-FABARA; CHARRO, 2017).

A digitalização se refere ao crescente uso de tecnologias digitais para conectar pessoas, empresas e sistemas (COREYNEN; MATTHYSSENS; VAN BOCKHAVEN, 2017). Com o advento da $4^{\text {a }}$ revolução industrial, a adoção de grandes esforços de digitalização está se tornando presente em quase todos os setores e, em certos casos, o digital está deixando de ser o suporte dos negócios para se tornar o próprio negócio. Com isso, é fundamental estabelecer uma presença digital para a continuidade dos negócios, 
valendo não somente para grandes empresas multinacionais, mas também para pequenas e médias empresas (LOUW; NIEUWENHUIZEN, 2019).

O comportamento do consumidor é muito diferente do que era visto há alguns anos (CARPIO et al., 2020). A facilidade com que os clientes podem compartilhar informações é uma característica importante que diferencia o ambiente online do ambiente de marketing tradicional. No meio digital, o boca a boca não é realizado apenas com amigos íntimos e pessoas da família, mas com um universo muito maior de pessoas que têm acesso aos comentários nas redes. Em redes sociais ou nos sites das empresas, por exemplo, clientes podem publicar suas análises de produtos, serviços, marcas e também das empresas. $\mathrm{E}$ essas informações e avaliações acabam atingindo um número grande de clientes em potencial (KANNAN; LI, 2017).

Mesmo a digitalização sendo uma tendência importante nos dias de hoje, Wang (2020) aponta que muitas organizações estão atrasadas em relação aos seus consumidores no meio online. Para sobreviver no mercado atualmente, uma integração da mídia digital nas práticas da empresa é necessária, transformando a interface de comunicação com os clientes, fornecedores e outros parceiros de canal. A tecnologia permite que as empresas tenham um acesso maior e imediato a clientes, fornecedores e membros de um canal como um todo. 0 grande desafio é conseguir gerenciar esses relacionamentos simultaneamente (WANG, 2020).

De modo a lidar com as crises enfrentadas e manter o negócio, as empresas veem a necessidade de optar por utilizar diversas estratégias no meio digital. Um exemplo bem atual é que o mundo inteiro está sofrendo em 2020 com os efeitos da Covid-19, responsável por um grave impacto na maioria dos setores e negócios. Essa e diversas outras crises acabaram por alterar o modo como as empresas fazem o marketing. A tecnologia foi a salvação para muitos problemas enfrentados pelos indivíduos e pelas organizações, proporcionando mudanças reais e impactando positivamente muitos aspectos da vida cotidiana e empresarial. Sem ela, muitos setores não conseguiriam continuar operando e atendendo seus clientes. Com as crises, vem a importância das instituições em considerar a inovação, utilizando de estratégias de digitalização. O investimento em tecnologias de análise de dados que permitam um melhor entendimento das percepções e opiniões dos consumidores sobre a mudança permite uma análise dos canais e níveis de serviço que são exigidos e podem ser ofertados aos clientes (DWIVEDI et al., 2020). Crise são momentos de instabilidade, que fogem da normalidade e ocorre um desequilíbrio (MACHADO; DURANTE; VIEGAS JUNIOR, 2019). Segundo os autores, elas podem se desenvolver de duas maneiras: de forma inesperada ou fruto de erros do dia a dia, que vão se agravando com o tempo.

Estudar estratégias de marketing digital acaba se tornando necessário para quem quer entrar ou permanecer no mercado. Sabe-se que as crises podem ser inesperadas. Por isso, é importante a 
existência de um plano de crise com meios que podem ser utilizados pelas organizações (MACHADO; DURANTE; VIEGAS JUNIOR, 2019). O ambiente digital é um espaço de visibilidade e legitimação da marca, necessitando de atenção e gerenciamento, de modo a se antecipar das crise, com o intuito de que elas não tomem proporções irreparáveis (MACHADO; BARICHELLO, 2015). Este artigo, então, tem o objetivo de analisar quais são as estratégias de marketing digital adotadas por organizações em diferentes situações de crise. Esta pesquisa torna-se relevante ao considerar o cenário atual da comunicação midiática, em especial a comunicação organizacional (MACHADO, 2016). Busca-se também colaborar com o meio empresarial, apontando diversas estratégias que podem ser adotadas tanto por organizações que se encontram ou aproximam de uma crise, como também por aquelas que desejam evita-las. Além disso, busca-se contribuir com estudos no âmbito acadêmico, principalmente com a área de marketing e relações públicas, fornecendo dados que possam contribuir com pesquisadores que analisam a transformação do ambiente físico para o digital, das mídias tradicionais para as virtuais e dos que buscam resoluções de casos que podem ser solucionados com alguma(s) das estratégias digitais apresentadas neste artigo.

\section{MARKETING DIGITAL}

As tecnologias digitais se espalharam rapidamente na maior parte do mundo (WORLD BANK, 2016). Com a globalização, a maioria das pessoas está imersa na era digital. Assim, as tecnologias vêm exercendo grande pressão sobre as empresas para que adaptem sua prática aos diversos mecanismos modernos existentes. Com isso, o Marketing digital se tornou uma ferramenta essencial para competir no mercado, sendo um meio eficiente para alcançar consumidores potenciais. O conceito de marketing digital foi utilizado pela primeira vez em 1990 tratando de publicidade aos clientes. O conceito foi ampliado com o surgimento de novas ferramentas sociais e dispositivos móveis durante as décadas de 2000 e 2010 (FIERRO; ARBELAEZ; GAVILANEZ, 2017). Kannan e Li (2017, p. 23) definem marketing digital como "um processo adaptável e habilitado para a tecnologia, pelo qual as empresas colaboram com clientes e parceiros para criar, comunicar, distribuir e sustentar valor para todas as partes interessadas".

Houve uma mudança de paradigma no marketing digital, saindo da publicidade e indo para o engajamento com foco no cliente (KANNAN; LI, 2017). Nos últimos anos, o marketing digital transformou a maneira como as organizações se comunicam com os consumidores. 0 aumento do uso das redes sociais deu origem a novos modelos de negócios baseados na bidirecionalidade da comunicação entre as empresas e os usuários da internet, gerando diversos comentários dos internautas no meio online (SAURA; PALOS-SANCHEZ; HERRÁEZ, 2020). De acordo com Kannan e Li (2017), o marketing digital evoluiu ao longo do tempo de um termo que descreve o marketing de produtos e serviços usando canais digitais para 
um termo abrangente que caracteriza o processo do uso de tecnologias digitais para alcançar clientes, criar preferências, promover marcas, manter clientes e aumentar vendas. Assim, um relacionamento digital com os consumidores tem se mostrado fundamental (FIERRO; ARBELAEZ; GAVILANEZ, 2017; MONTARDO; ROSA, 2008).

As redes sociais se tornaram o instrumento de comunicação online mais popular, permitindo a construção de redes e gerando interação entre as pessoas. Como são plataformas na qual um grande número de pessoas está conectado compartilhando suas experiências e devido aos seus custos baixos, esse tipo de comunicação virtual também é um método conveniente para empresas que não possuem alto orçamento para investir no Marketing digital. Nas redes sociais, as empresas são capazes de promover sua marca, produtos e serviços, se conectar com seus clientes e conquistar novos por meio de baixo investimento financeiro (FIERRO; ARBELAEZ; GAVILANEZ, 2017). Além disso, muitos indivíduos são altamente conectados com suas redes sociais e assim, estão propensos a autoidentificação com a marca, podendo difundi-la para seus seguidores (BUSCA; BERTRANDIAS, 2020).

As contas dos usuários e as suas interações constantes permitem que as plataformas criem um perfil detalhado de seus gostos, interesses, hábitos e outras características do usuário. Uma segmentação detalhada foi possibilitada com a facilidade de rastrear um usuário ou um grupo específico de acordo com seus comportamentos e interesses (MARÍN LOÓPEZ; LÓPEZ TRUJILLO, 2020). Assim, o marketing digital personalizado ou individualizado, uma estratégia na qual negócios em ambiente online utilizam de dados para entregar mensagens individuais aos clientes existentes e potenciais, se tornou uma boa opção para chegar aos usuários. Quando usada corretamente, a personalização pode trazer resultados positivos para os negócios da empresa, fazendo com que os consumidores se sintam especiais, levando-os a comprar ou até mesmo a se tornarem fiéis à marca (BEHERA et al., 2020).

O ambiente digital é responsável por produzir uma gama infinita de dados que vão desde o fluxo de cliques, avaliações de clientes, tags, blogs e dados de interação social, até respostas de clientes às ações de marketing implementadas e informações sobre colaboradores e concorrentes. Esses dados são muito informativos para que as empresas entendam o comportamento do cliente online, meçam a eficácia de suas ações e desenvolvam estratégias de marketing adequadas para o público desejado (KANNAN; LI, 2017). Porém, o desafio é como analisar os dados e utilizá-los para otimizar seus processos (MARÍN LOÓPEZ; LÓPEZ TRUJILLO, 2020). Os recursos limitados acabam por limitar as empresas, principalmente as menores ou as que estão em um momento de crise, fazendo com que escolhas sejam feitas, podendo o marketing digital e análise de dados não parecerem prioritários, mesmo se mostrando de grande importância (LOUW; NIEUWENHUIZEN, 2019). Muitas vezes é necessária uma mudança na mente dos 
gerentes quando se tem o reconhecimento de oportunidades de negócios que envolvem estratégias de marketing digital (BUSCA; BERTRANDIAS, 2020).

\section{METODOLOGIA}

De modo a atingir o objetivo proposto na presente pesquisa, foi realizada uma revisão integrativa, um tipo de pesquisa que utiliza como fonte de dados a literatura sobre determinado tema, gerando novos conhecimentos sobre o tópico revisado. A revisão integrativa analisa, critica e sintetiza a bibliografia de uma maneira integrada, de modo que novas estruturas e perspectivas sobre o tema sejam geradas (TORRACO, 2016). De acordo com Cooper (1988), as revisões podem ser organizadas de maneira conceitual, histórica ou metodológica. Esta revisão integrativa é organizada conceitualmente, de modo que a literatura que aborda as mesmas ideias é revisada em conjunto.

O delineamento metodológico desta pesquisa foi realizado por meio de três fases: (1) procedimentos de busca e seleção; (2) critérios de seleção; e (3) análise semântica dos artigos.

O procedimento de busca e seleção, que ocorreu em agosto de 2020, sendo realizado nas bases de dados internacionais, Web of Science e Scopus, e nas nacionais, SPELL e SciELO, dado que são repositórios de grande abrangência de documentos. A busca nas bases de dados internacionais consistiu em palavraschaves em inglês, sendo estas, "digital marketing strateg" ," "digital marketing" e strateg*, "digital marketing", "digital strateg*", crisis, slump e depression, utilizando a busca por tópicos, que englobam o título, resumo e palavras-chaves. Nas nacionais, foram utilizados os termos em português estratégia (s) de marketing digital, marketing digital, estratégia (s) digital (is) e crise, sendo ambas a busca pelo resumo, opção possibilitada pelas bases, para se ter uma garantia maior de que os artigos sejam focados no escopo do artigo. Os critérios de seleção pressupunham que, se nenhum desses termos aparecesse no título, resumo ou palavras-chaves, era provável que as estratégias de marketing digital em situações de crise não ocupassem uma posição central no artigo e, portanto, poderia ser excluído. Operadores booleanos, bem como outros tipos de operadores, foram utilizados como forma de melhor refinar a pesquisa.

Em relação aos critérios de seleção, foram adotados os seguintes procedimentos: (i) foram selecionados apenas artigos resultando em 31; (ii) não houve seleção de ano e áreas, sendo considerados todos os artigos encontrados na busca; (iii) foram removidos 9 artigos duplicados; e (iv) excluídos 9 artigos após a leitura dos mesmos por não corresponderem ao escopo da pesquisa. Assim, foram selecionados 13 artigos para a análise semântica.

Na terceira fase, a análise semântica, foi realizada uma análise qualitativa dos 13 artigos que se encaixaram no objetivo do trabalho. Foram analisados: (i) os tipos de crise estudados nos artigos da 
amostra e (ii) as estratégias de marketing digital utilizadas pelas organizações durante a crise. Dentre os artigos excluídos por não estarem no escopo desta revisão estão o de Veiga (2014) que trata dos impactos da crise econômica na imagem de Portugal como destino turístico e o de Matei e Savulescu (2012) que aborda sobre a crise econômica e financeira de 2008 e analisa o setor de tecnologias da informação e comunicação da União Europeia entre 2006 e 2010. São artigos relevantes que trazem discussões sobre as crises enfrentadas. Porém, não trazem estratégias de marketing adotadas, mas citam a sua importância para como uma das ações a serem tomadas. Acredita-se que por se tratarem de artigos publicados há mais de cinco anos, já se sabia da importância e do crescimento, mas a internet ainda não havia o poder e o domínio que possui hoje. Com isso, as empresas ainda não estavam habituadas a ver como algo comum atuar no meio online. Foram, então, selecionados para a análise integrativa treze artigos que apresentam estratégias e debates interessantes sobre como lidar com a crise.

\section{RESULTADOS E DISCUSSÃO}

Os resultados estão estruturados em três subseções. A primeira subseção apresenta os diversos tipos de crise encontrados nos artigos analisados. A segunda subseção abrange as estratégias de marketing digital utilizadas pelas organizações que se encontravam em situações de crise. A terceira e última apresenta o framework desta pesquisa sintetizando o que foi encontrado e analisado.

\subsection{CRISES}

\subsubsection{Crise do jornal impresso}

A indústria jornalística passou por uma grande crise financeira na última década devido ao avanço da digitalização. Este artigo analisa dois casos, um nos Estados Unidos e outro na Espanha. Nixon (2020) realizou um estudo de caso com uma empresa jornalística norte-americana, a MediaNews Group, de modo a analisar os esforços da empresa para criar fontes de receita, examinando as estratégias adotadas no período de 2006 a 2016. Na primeira década dos anos 2000, a empresa tinha uma estratégia simples. Ela começou a adquirir vários jornais nas áreas metropolitanas de Los Angeles e San Francisco a fim de criar grupos regionais que aumentassem o número de consumidores dependentes de suas notícias, enquanto reduziam os custos de produção e divulgação destas notícias. A MediaNews parecia estar tendo sucesso no ramo de notícias impressas, porém quando a crise atingiu a indústria jornalística nos Estados Unidos, ela declarou falência. Pouco tempo depois, foi fundida com outra rede de jornais que tentou responder 
à crise no mercado de notícias impressas se concentrando no desenvolvimento de meios apresentar as notícias em formato digital.

O negócio de notícias opera, em sua essência, em uma economia de atenção, em que a atenção, um recurso escasso quando a informação é abundante, é a fonte de valor que gera receita por parte dos consumidores de notícias ou anunciantes. Assim, a MediaNews percebeu que é a capacidade de controlar as condições de consumo das notícias que torna possível ganhar poder sobre a atenção, tratando o prestar atenção às notícias como o trabalho explorável da empresa (NIXON, 2020).

Prado (2015) analisa os desafios que a imprensa catalã enfrentou com o modelo de negócios exclusivamente impresso. Os jornais pagos eram o tipo de imprensa que exercia maior influência na formação de opinião pública catalã devido à sua grande audiência e ao seu foco em assuntos atuais e especialização na política local. Assim, os jornais da Catalunha, na Espanha, enfrentavam um duplo desafio: a crise no modelo de negócios exclusivamente impresso e o declínio das receitas, que tinha duas causas principais, a queda no número de leitores e no financiamento da publicidade. A primeira causa envolve a perda significativa de distribuição e de leitores desde o início do século atual, com queda de $27,3 \%$ entre 2000 e 2012. Já sobre a segunda causa, a taxa de despesas com publicidade tem caído continuamente desde o início da crise e, no ano de 2015 em que foi escrito o artigo, não havia ainda atingido seu maior declínio. Entre 2007 e 2012, caíram 59,21\% os gastos com publicidades em jornais. Com isso, a autora apresenta o caso de um jornal da Catalunha, o ARA, lançado em 2010, que obteve sucesso com suas estratégias digitais.

A mudança para meios cada vez mais digitais de produção, circulação e consumo de notícias trouxe desafios para a indústria jornalística. Após uma resistência inicial, em resposta à crise no modelo de negócios de mídia impressa, as editoras de jornais acabaram tendo que optar por utilizar estratégias digitais. 0 setor jornalístico então, ampliou sua diversidade de produtos além do jornal impresso. A principal preocupação era levar as notícias para o ambiente online através dos sites e aplicativos de seus jornais, apostando nas assinaturas digitais.

O jornal da Catalunha, ARA, analisado por Prado (2015), optou por um conceito moderno que combinava uma estratégia digital com a edição impressa. A estratégia digital multiplataforma contava com o site do jornal com atualizações constantes, aplicativos para dispositivos móveis e atividades nas redes sociais. Em três anos eles alcançaram um grande número de assinantes, ultrapassando 20 mil. 0 pagamento poderia ser realizado para compras de unidades digitais, assinaturas digitais ou assinaturas de jornais em papel. As assinaturas dos produtos digitais têm custos muito menores e podem ser combinadas com o acesso às versões impressas. Para captar os leitores, os assinantes dos jornais impressos também possuíam acesso a todos os produtos digitais. O sucesso da sua estratégia digital também pode ser visto 
no número de seguidores que o jornal possuía nas redes sociais, sendo 140 mil no Twitter e quase 9 mil no Facebook. Porém, a autora aponta que essas estratégias acabam encontrando barreiras. Para que se tenha lucros altos com assinaturas digitais, é necessário que o modelo de pagamento pelo consumo supere a cultura da internet gratuita, que é muito enraizada na Catalunha e em tantos outros lugares. A audiência online paga é claramente superestimada em relação às edições impressas.

As estratégias da empresa jornalística norte-americana MediaNews (NIXON, 2020) vão além das implementadas pela catalã. Ela iniciou um forte incentivo para seus leitores adotarem o consumo de notícias digitais, uma vez que a produção e a circulação digital têm o custo muito menor, interrompendo a entrega em domicílio de muitos de seus jornais. Além de apostar nas assinaturas digitais em seus sites e aplicativos, também contou com o envolvimento do público enviando notícias e com a publicidade online, que gerou grande receita para a empresa. Ela investiu em anúncios direcionados na publicidade digital, provendo aos anunciantes a capacidade de atingir mais de 400 segmentos por localização, sexo, idade e interesses, como notícias, negócios e esportes, permitindo assim uma segmentação personalizada em sua publicidade.

A MediaNews tentou estender a dependência de séculos do capital dos seus jornais nas receitas de publicidade no meio digital. Embora a geração de receita por meio da publicidade digital não seja tão grande quanto por meio da publicidade impressa, sendo isso um dos aspectos centrais da crise da indústria jornalística, a receita da publicidade continuou sendo uma fonte importante de acumulação de capital para as empresas de notícias. A publicidade digital representa a maior parte da receita na internet da indústria jornalística nos Estados Unidos. De acordo com estimativas, apenas no ano de 2012, esse setor gerou US\$3,4 bilhões em publicidade online contra US\$100 milhões em assinaturas apenas digitais. Mesmo sem perspectivas de que o jornal recupere suas altas taxas de publicidade impressa, a publicidade digital continua sendo a base mais sólida para o ramo. Outro ponto é que, assim como outras indústrias de comunicação, a indústria de jornais viu que a digitalização do conteúdo e as práticas de consumo diminuíram a sua capacidade de controlar o acesso e determinar as condições de consumo. Com isso, a MediaNews viu a necessidade de investir em uma parceria para cuidar dos direitos autorais de suas notícias (NIXON, 2012).

Prado (2015) conclui que, mesmo com todas as estratégias sendo adotadas no meio digital, a audiência no ambiente online ainda não é segura, não tendo um modelo de negócios definitivo para os jornais na era digital. Por mais que muitas estratégias neste ramo venham apresentando sucesso, elas ainda são uma tentativa de conseguir alcançar os lucros do antigo modelo de negócios com jornais impressos vendido em massa. 


\subsubsection{Crise da Covid-19}

A pandemia modificou muitos aspectos da vida diária, tendo os governos em todo o mundo que tomarem medidas submetendo seus cidadãos a longos períodos de confinamento. Isso teve um grande impacto na vida pessoal dos indivíduos, mas também dentro das organizações que tentavam manter suas operações durante a pandemia. Uma mudança radical nas formas de trabalho foi necessária, optando por trabalho remoto utilizando sistemas digitais de comunicação e a repensar completamente os seus modelos de negócios com a nova realidade (DWIVEDI et al., 2020).

Os sistemas de saúde também têm lutado com o grande desafio global que é a Covid-19. Enfrentam uma expansão crescente de óbitos e pacientes em estado crítico. Com isso, medidas extremas de quarentena foram e ainda estão sendo realizadas em muitos países (CAETANO et al., 2020). Em uma resposta restritiva, os governos de muitos países no mundo fecharam os locais sociais das nações, interromperam eventos, atividades esportivas e mudou grande parte da força de trabalho empresarial para operar em ambientes domésticos. Muitas empresas sofreram com esse novo modelo de trabalho durante meses, tendo grande prejuízo ou até mesmo indo à falência (HAMILTON, 2020). A pandemia do coronavírus forçou muitas organizações a passar por uma transformação significativa, tendo que repensar os elementos-chave dos seus processos de negócios e o uso de tecnologia para manter suas operações, aderindo a um novo cenário com mudanças de diretrizes e novos procedimentos (DWIVEDI et al., 2020).

Hamilton (2020) realizou um estudo a empresa australiana de marketing digital DUK, líder em tecnologia. Durante a crise econômica gerada pela pandemia global do coronavírus, a empresa se viu em problemas ao perder clientes que tiveram suas atividades abaladas ou paralisadas com os danos econômicos consideráveis que o setor empresarial australiano sofreu, gerando um choque em toda a economia do país. Em poucas semanas, muitos dos principais clientes da DUK reduziram ou até mesmo cessaram as negociações com a empresa. Alguns deles continuaram seus negócios operando com o que conseguiam fazer com seu próprio marketing e publicidade. Era uma cadeia, uma redução de serviços e clientes atingindo todos os envolvidos. Assim, cerca de 70\% da receita da DUK, que suportava mais de 30 profissionais de marketing de alta qualificação, desapareceu em dois meses. Assim, a DUK buscou reajustar seus negócios e emergir em uma posição competitiva sustentável.

Dwivedi et al. (2020) analisa uma visão coletiva de doze especialistas debatendo sobre a crise da Covid-19 e seus impactos nas organizações e na sociedade, trazendo discussões com uma perspectiva tecnológica. Diversos são os tópicos analisados, desde a mudança global no ensino superior, fechando as universidades e optando pelo ensino online, a negócios no meio digital, utilizando diferentes plataformas, e também inovações necessárias na área da saúde em todo o mundo. De modo a atender o escopo deste 
artigo, foram selecionados os casos de estratégias digitais citados como forma de tentar contornar a crise do coronavírus.

Caetano et al. (2020) traz um debate sobre os desafios e oportunidades para a telessaúde no Brasil durante a pandemia do coronavírus. Esse campo tem crescido acentuadamente nos últimos anos, mas sempre enfrentou muitas normas para a sua realização. Com a pandemia, um marco importante, houve uma expansão das aplicações e usos da telessaúde no país como forma de melhorar a resposta do sistema de saúde à crise enfrentada. Ela pode trazer diversos benefícios, como a redução da circulação de pessoas nos hospitais, do tempo de atendimento, dos custos de deslocamento dos pacientes e dos profissionais de saúde, conseguindo acessar pacientes de diferentes localidades e também entregando maior qualidade com o acesso a profissionais especialistas de maneira remota. Várias estratégias envolvendo tecnologias digitais foram adotadas e analisadas neste artigo.

Ting, Ling e Cheah (2020) examinam as oportunidades que profissionais e acadêmicos podem aproveitar durante a pandemia do coronavírus. Os autores abordam dicas para profissionais de marketing que já atuam no mercado e para os indivíduos que desejam abrir seus negócios durante a crise. Devido à amplitude da pandemia, as atividades e estratégias de negócios precisam ser reconsideradas e, embora as abordagens apresentadas não sejam novas para o marketing digital, devem ser avaliadas e planejadas para se obter sucesso nos negócios.

Durante a crise da Covid-19, que resultou em uma rápida redução nas atividades econômicas de muitos dos seus principais clientes, a DUK, empresa de marketing digital australiana de tamanho considerável, em uma análise das competências, capacidades e competitividade da empresa e atuando com uma matriz de mudança estratégica, conseguiu realinhar seu empreendimento com as mudanças nos mercados de clientes tradicionais de modo a buscar um novo caminho de melhoria e se tornar um negócio competitivo e sustentável. A DUK alavancou suas competências para aplicar as capacidades dos seus clientes no intuito de gerar um alcance adicional de consumo físico e digital e, com isso, melhorias subsequentes nas vendas. Atuando com consultores de gerenciamento contínuo com seus clientes e como estrategista de marketing físico e digital, diferente de seus concorrentes, a DUK conseguiu se adaptar e construir vantagem com estratégias criativas de vendas, se tornando uma empresa de marketing digital otimizada. Esses resultados foram fruto de mudanças como: um novo software, novo uso de dados, novo mapeamento logístico, novo gerenciamento de painel, nova qualificação da força de trabalho, novas vendas e segurança de carteira digital e também uma nova imagem da marca. Essas mudanças permitiram a DUK mapear e entregar um conjunto de soluções defensivas e de apoio aos seus clientes e também mapear seus próprios avanços de mudança estratégica para aumentar e diversificar sua participação no mercado, tendo uma estrutura interna capaz de fazer a empresa avançar no sentido de manter a sustentabilidade 
do seu negócio. Assim, com a crise do Covid-19, o cenário de negócios australianos mudou, criando novos modelos de negócios, mais complexos, com maior capacidade de rotação e mais competitivo.

Ting, Ling e Cheah (2020) trazem dicas de como se portar nas mídias sociais durante a pandemia para aqueles que já atuam e para os que pretendem entrar no mercado. Além de adotar novas plataformas online para fazer negócios e se conectar aos seus clientes, os autores apontam que o produto deve ser apresentado com empatia e transparência. Durante a pandemia, os consumidores estão confusos e vulneráveis e geralmente estão mais dispostos a tolerar pequenos erros ou atrasos. As mídias sociais devem ser usadas de maneira ágil e com criatividade. Para dinamizar as mensagens, uma boa opção é apostar em modelos operacionais de resposta mais rápida internamente ou por meio de agências. Iniciativas para promover o distanciamento social e que manifestem compromisso com a segurança pública é de grande importância para a imagem da marca. Além disso, compartilhar conteúdos que aliviem a ansiedade e promovam uma reação positiva diante da crise, gerando bem-estar é estratégia para a marca ser associada a algo bom, fazendo com que os consumidores se lembrem de seus atos futuramente.

Dwivedi et al. (2020) trazem um debate sobre o afastamento causado no ambiente de trabalho devido à pandemia do coronavírus. Quando separados trabalhando remotamente em suas casas, os colaboradores podem se sentir cada vez mais desconectados de seus colegas de trabalho e do emprego. As potenciais implicações negativas da solidão nos indivíduos podem ser profundas. Pode resultar em diversas consequências, como redução no seu compromisso com o trabalho, sentimentos de solidão, ansiedade, depressão, se sentir fora dos processos de tomada de decisão da empresa, perda de confiança e motivação e queda da produtividade. Com isso, os autores trazem exemplos de aplicativos para dispositivos móveis que são utilizados pelas empresas para que seus funcionários tenham uma maior sensação de estar socialmente presentes, podendo ver, ouvir e interagir com os demais. Isso traz um outro ponto importante nesta pandemia. A preocupação está principalmente em como atender os seus consumidores, mas e os seus funcionários? Eles estão desfrutando de um ambiente de trabalho saudável?

Aplicativos de rastreamento, monitoramento e estudo de sintomas foram analisados por Dwivedi et al. (2020) durante a pandemia do coronavírus. Dentre as estratégias digitais utilizadas, vários sistemas e aplicativos foram utilizados para conseguir fiscalizar a população. Como citado no Quadro 2, para smartphones, foram criados aplicativos na Índia, em Cingapura e no Reino Unido utilizando tecnologias bluetooth e GPS. Também foi criado um sistema de monitoramento na Índia controlando o movimento dos veículos. Além de conseguir rastrear os indivíduos doentes, os aplicativos colaboravam com estudos dos sintomas da Covid-19.

Outra inovação simples e interessante que contribuiu com a área da saúde foi a 'Chamada perdida' realizada na Índia pelo governo em parceria com um instituto indiano. Essa estratégia contou com um 
uso de sistema de resposta de voz interativo. Esse sistema contou com um grande número de respostas, chegando a receber 1500 ligações nos primeiros dias da crise. Além do atendimento à população, as empresas de telecomunicação passaram a colocar melodias com mensagens de prevenção ao coronavírus nas ligações de modo a conscientizar sobre a infecção.

Caetano et al. (2020) discute a contribuição da telessaúde para lidar com a Covid-19 e as iniciativas que foram adotadas no Brasil. Ela oferece capacidades para triagem, consultas virtuais oferecendo tratamentos e cuidados remotos e auxiliando na vigilância, detecção, na prevenção e no monitoramento da doença. Essas iniciativas, além de colaborar com a enfrentamento do coronavírus, fazem parte de um processo que tende a colaborar com a reconfiguração do espaço futuro da telemedicina no país.

\subsubsection{Crise do turismo}

Com a expansão do terrorismo na Europa desde 2014, Avraham (2020) buscou analisar a crise do turismo após os ataques terroristas e as estratégias de reparo de imagem dos destinos utilizadas pelas autoridades europeias. 0 autor afirma que até o momento somente foram realizados estudos de caso isolados, sendo necessário um estudo de casos múltiplos sobre a temática. Com isso, através de uma análise qualitativa de vários conteúdos de mídia, incluindo anúncios e campanhas de recuperação, iniciativas de marketing, relatórios de mídia e entrevistas com autoridades europeias, a pesquisa examina as estratégias utilizadas para tentar recuperar os turistas após 89 ataques terroristas em destinos europeus entre 2014 e 2019.

Avraham (2020) traz a internet como alternativa para a mídia tradicional. Pelos governantes e empresários acreditarem que as mídias tradicionais estariam exacerbando a crise, fazendo-a parecer maior, passaram a investir em outros meios, como a internet. O principal objetivo dessa estratégia seria contornar a mídia tradicional e atingir o público estrangeiro por meio de mídias alternativas, sendo principalmente por seus sites e redes sociais, mas também por incentivo a sediar eventos, conferências e gravação de filmes e séries de televisão no destino destacando atrações, de maneira a mostrar que tudo estava voltando ao normal após os ataques, transmitindo, assim, uma mensagem de segurança, com o intuito de persuadir o público a visitar. Além deste caso apresentado, a internet é comumente utilizada como a alternativa mais viável devido a apresentar custo mais baixo do que as mídias tradicionais e por trazer a possibilidade de atingir novos públicos com uma segmentação personalizada.

Diversas estratégias digitais foram adotadas com a crise do turismo após os ataques terroristas na tentativa de transmitir a mensagem de que tudo estaria voltando ao normal. Entre estas foi a alocação de recursos para seus sites e redes sociais. Campanhas foram criadas com divulgação do destino turístico e competições entre os visitantes compartilhando suas fotos durante a viagem com hashtags, como por 
exemplo, \#ParisWeLoveYou. Além das campanhas, foram realizados convites para blogueiros e youtubers de vários países irem conhecer e visitar a França. Uma estratégia inteligente que atinge os seguidores dos viajantes. Além de despertar o desejo, passa a ideia de que tudo está seguro novamente, as atrações estão abertas, os serviços turísticos estão funcionando normalmente e não há motivos para não visitar. Outra campanha interessante para os que estariam mais receosos com a segurança foi a realizada por Bruxelas, colocando telefones pela cidade em que os turistas poderiam ligar e conversar com os moradores locais em chamadas de vídeo, com o intuito de mostrar que a vida voltou ao normal nos destinos.

\subsubsection{Crise dos refugiados}

A crise dos refugiados é abordada por Pettersson e Sakki (2017) ao tratarem das estratégias discursivas e digitais utilizadas por políticos nacionalistas neste período. Em 2015, na maior crise global de refugiados desde a Segunda Guerra Mundial, mais de um milhão de migrantes de países em guerra cruzaram as fronteiras europeias em busca de condições melhores e mais seguras. Isso gerou uma grande turbulência dentro da União Europeia, gerando visões conflitantes e dividindo entre os que desejavam abrir ou fechar as fronteiras nacionais para os imigrantes. O fracasso dos políticos no poder acabou proporcionando uma oportunidade para os partidos de direita radical de toda a Europa lançarem promessas de proteção do povo contra a ameaça da imigração em massa descontrolada. Assim, neste artigo, os autores propõem uma nova forma de analisar o novo discurso de políticos populistas de direita radical a partir de uma perspectiva qualitativa, analisando postagens nos blogs de políticos famosos por seus argumentos contra a imigração e o multiculturalismo.

Entender sobre estratégias discursivas é outro ponto importante para as organizações que querem realmente tocar o seu público alvo. Os blogs políticos perceberam que podem ser canais poderosos para expressar visões políticas nacionalistas e anti-imigração. Através de uma mistura de elementos verbais, visuais e digitais, novas formas de retóricas podem ser assumidas e utilizadas em seu favor para atrair o eleitorado, caso também ocorrido no Brasil com o atual presidente Bolsonaro que preparou sua eleição através das redes sociais. Por meio de dois exemplos de posts de políticos que, utilizando estratégias discursivas, apresentando fatores econômicos e sociais, demonstram racionalidade e imparcialidade, se passando como representantes que se preocupam com o bem-estar da nação, Pettersson e Sakki (2017) mostram como as mensagens construindo uma imagem de nação sob ameaça são transmitidas por meio de uma multiplicidade de elementos apresentados nos blogs, demonstrando a persuasão da política contemporânea. 


\subsubsection{Crise do imediatismo}

Atualmente, as empresas estão enfrentando a crise do imediatismo, que se trata da necessidade que os consumidores têm de receber conteúdo e soluções personalizadas em tempo real durante a sua experiência de compra. 0 mundo passou a ser voltado para o cliente, podendo ele ditar muito do conteúdo desejado. Os varejistas não conseguem mais ser observadores passivos esperando que o seu produto encontre um comprador. Hoje existe a necessidade de atendimento com conteúdo imediato e personalizado a qualquer hora e em qualquer lugar. Parise, Guinan e Kafka (2016) analisam em seu estudo estratégias de como atender a essa necessidade gerando experiências individualizadas e imersivas, permitindo interatividade e uma rica troca de informações entre a marca e o consumidor no momento da aquisição. A pesquisa contou com dados de mais de 35 varejistas de diferentes setores acerca do uso de tecnologias para interagir e transformar a experiência dos clientes em diferentes canais.

Analisando a crise do imediatismo, a pesquisa de Parise, Guinan e Kafka (2016) aponta que existem dois estímulos de tecnologia que podem levar a uma rica experiência do cliente: a personalização e a interatividade. Com isso, as descobertas mostram dois modelos principais baseados em tecnologias que as organizações estão implantando com o objetivo de dar suporte às necessidades imediatas dos clientes, podendo a empresa optar por um ou por ambos, a depender de suas necessidades: o assistente digital e o especialista remoto, dois modelos com diferentes tipos de interação, conforme apontado no Quadro 2. O especialista remoto é muito utilizado para ajudar os consumidores na jornada de pré e pós-compra. Os consumidores podem tirar suas dúvidas imediatamente gerando uma forte interação e motivação à compra ou a uma recompra, além de confiança na marca. Geralmente esse modelo é uma boa opção em situações urgentes e de crise, em que o cliente precisa se conectar imediatamente com a empresa. 0 assistente digital permite que os varejistas tenham a capacidade de adquirir dados comportamentais dos consumidores, seus interesses, quando compram e quais tipos de conteúdo levam à conversão. Além disso, é possível enviar conteúdo personalizado para o smartphone do cliente, capturar dados como horários de pico de compras, relação entre vendas e produtos da loja.

\subsubsection{Crise das lojas físicas}

O uso constante da internet no dia a dia das pessoas trouxe uma onda de compras online e marketing digital. Com isso, os proprietários de lojas físicas têm presenciado cada vez mais a migração das lojas do varejo para as lojas online tão rapidamente acessíveis. Diante disso, Giridhararajan et al. (2020) realizaram um estudo sobre a crise das lojas físicas com a facilidade encontrada pelos consumidores com as compras em um clique. Os autores questionam se essa mesma tecnologia que causou a crise no setor de varejo 
poderia ser usada para levar os clientes as suas lojas. Anúncios tradicionais em rádio, televisão e internet podem parecer atraentes, mas não têm o poder de direcionar as decisões dos consumidores. Assim, propõem estratégias para que seja possivel contornar a crise com diferenciais que trazem vantagem competitiva.

Com a crise do varejo pela grande migração dos consumidores para lojas online, a tecnologia acabou tendo que sair do papel de vilão para aliado. Utilizando sistemas de detecção de proximidade e de recomendação de produto, Giridhararajan et al. (2020) trazem estratégias que juntas conseguem gerar estímulos e direcionar os consumidores às compras: os sistemas de detecção de proximidade e os sistemas de recomendação de produto. Se conectar aos clientes enquanto eles estão próximos a pontos de venda ou a seções de uma loja e despertar o interesse fazendo-os ir ao encontro do que é proposto é o principal objetivo do sensor de proximidade. Ele visa atingir os clientes com anúncios apoiados pela proximidade dos consumidores e seus dispositivos móveis a uma seção específica. Essas estratégias trazem uma nova vida às lojas físicas, tornando praticamente todos os consumidores com um telefone celular, produto que a maioria da população já possui, cada vez mais abertos a uma estratégia de marketing de proximidade e recomendação. Basta que o smartphone esteja com a localização ativada ou conectado à internet (GIRIDHARARAJAN et al., 2020).

\subsubsection{Crise de marcas globais}

Com a globalização e o crescimento da internet, o boca a boca se tornou ainda mais poderoso. A possibilidade de incitar um debate de grande proporção nas mídias sociais faz com que os assuntos ganhem grande dimensão. De acordo com Salvador, Strehlau e Ikeda (2015), a juventude e o avanço das telecomunicações constituíram os principais propulsores para as marcas globais, aumentando a visibilidade e dinamizando a comunicação com seus consumidores. Os autores, então, trazem em seu artigo uma discussão sobre a repercussão de uma crise local de uma empresa global em outros mercados e sua relação com as redes sociais. A crise analisada foi causada pela morte de um funcionário na construção do estádio de abertura da Copa do Mundo de 2014 em São Paulo. A FIFA e a World Cup são as marcas globais envolvidas. Assim, foi realizado um monitoramento do assunto, realizando uma análise de conteúdo dos posts nas redes sociais entre 01/04/14 e 16/04/14, período da repercussão.

De acordo com Guo, Ding e Lanshina (2017), após a crise global de 2008-2009, as indústrias digitais têm sido as mais promissoras e dinâmicas da economia global e, pelo mundo não ter encontrado um equilíbrio entre os benefícios e os riscos da economia digital, é necessária uma governança global nesse âmbito. Assim, os autores analisam as características do G20 na esfera da governança global na economia digital, destacando as estratégias que precisam ser seguidas para garantir a segurança cibernética, 
eliminar distorções entre países desenvolvidos e em desenvolvimento e alcançar qualidade de vida para todos, conforme é apontado no Quadro 2. Todas as estratégias discutidas pelo G20, dentre elas, valorizar o investimento em infraestrutura de banda larga, melhorar a taxa de penetração da internet e colocar ênfase na integração da indústria da internet com outras indústrias, visam o desenvolvimento da economia digital, pois reconhecem que nos próximos anos, ela será o motor vital da economia mundial.

Wibowo A., Santoso e Wibowo M. (2020) abordam como as micro, pequenas e médias empresas podem ter a capacidade de colocar em prática o empreendedorismo e a inovação e serem resilientes em condições de crise econômica. Em um estudo na Indonésia, os autores trazem que através da colaboração de vários setores, incluindo o governo, foi criado um programa de educação para o empreendedorismo com o objetivo de capacitar as micro, pequenas e médias empresas quanto à gestão da informação estratégica, se adaptando ao marketing digita e aos produtos no ambiente online. Foram realizados seminários e disponibilizados materiais para mais de 12 mil empreendedores contendo diversas estratégias que poderiam ser utilizadas, entre elas, como se relacionar no ambiente digital, como anunciar promoções por meio de fotos e vídeos criativos dos produtos, tornando sua oferta atrativa no site, e-commerce e redes sociais. A educação para o empreendedorismo através de programas de capacitação, oferecendo oportunidades para uma maior participação de mercado, se mostrou um grande instrumento para colaborar com a economia local.

Salvador, Strehlau e Ikeda (2015) trazem o debate da crise local de empresas globais que acabam atingindo outros mercados por meio das mídias sociais. O caso da morte do funcionário na construção do estádio de abertura da Copa do Mundo de 2014 em São Paulo, envolvendo a FIFA e a World Cup, gerou repercussão em mais de 34 países e envolvia posts considerados funcionais, somente divulgando a informação, e postagens apresentando aspectos funcionais e emocionais, gerando envolvimento que, além da informação, o emissor da mensagem também realizava uma crítica ou juízo de valor. Além da crise das marcas globais FIFA e World Cup, os autores também relembram a crise enfrentada pela Coca Cola após a denúncia da existência de um rato morto em uma garrafa do refrigerante, caso famoso que se espalhou nas redes sociais e gerou grande repercussão. Esses casos devem ser examinados buscando a melhor saída o mais rapidamente, pois são crises que podem deixar um efeito residual na marca, a deixando frágil perante outras crises, podendo afetar outros produtos da empresa, os produtos concorrentes ou até mesmo a categoria como um todo.

\subsection{ESTRATÉGIAS DE MARKETING DIGITAL}

Nesta subseção são apresentadas as estratégias de marketing digital utilizadas pelas organizações em crise estudadas, conforme pode ser visto no Quadro 1. 


\section{Gestãoe \\ Desenvolvimento}

\section{Quadro 1 - Estratégias de marketing digital realizadas pelas organizações em crise}

\begin{tabular}{|c|c|}
\hline $\begin{array}{l}\text { Estratégias de } \\
\text { Marketing Digital }\end{array}$ & Descrição \\
\hline Site & $\begin{array}{l}\text { Criação e atualização constante do conteúdo a ser disponibilizado no site } \\
\text { da organização, como produtos, promoções, novidades. }\end{array}$ \\
\hline $\begin{array}{l}\text { Atuação nas redes } \\
\text { sociais }\end{array}$ & $\begin{array}{l}\text { - Uma das estratégias utilizadas pelo jornal catalão ARA foi investir em } \\
\text { atividades nas redes sociais, que com seus conteúdos, atingiu } 140 \text { mil } \\
\text { seguidores no Twitter e quase } 9 \text { mil no Facebook (PRADO, 2015). } \\
\text { - Após os ataques terroristas, os governantes europeus optaram por alo- } \\
\text { car recursos para monitoramento de mídia social em diversos idiomas } \\
\text { e em muitos países. As mensagens incorretas ou negativas foram com- } \\
\text { batidas com a ajuda de um gerente de mídia social em tempo integral, } \\
\text { atuando no Facebook, Twitter e Instagram (AVRAHAM, 2020). } \\
\text { - Na pandemia do coronavírus, houve uma intensificação do uso das } \\
\text { mídias sociais como o Twitter, Facebook e Whatsapp de autoridades de } \\
\text { saúde do Brasil fornecendo dicas de cuidados, informações diversas, es- } \\
\text { clarecimento de dúvidas sobre a doença e atualizando os casos diaria- } \\
\text { mente (CAETANO et al., 2020). } \\
\text { - Além de adotar novas plataformas para negócios online, aprender a se } \\
\text { portar nas mídias sociais durante a pandemia é essencial para um bom } \\
\text { relacionamento com o cliente. É preciso ser ágil e ter criatividade. Dois } \\
\text { exemplos são a Nike com a mensagem "Brinque por dentro, brinque pelo } \\
\text { mundo" e o McDonald's abrindo seus arcos dourados em uma foto com } \\
\text { a mensagem "Já estou em casa". Para dinamizar as mensagens, uma boa } \\
\text { opção é apostar em modelos operacionais de resposta mais rápida in- } \\
\text { ternamente ou por meio de agências. O compartilhamento de conteúdo } \\
\text { que manifeste preocupação com a situação ocasionada pela pandemia e } \\
\text { promova sensação de bem-estar é algo benéfico para a marca tanto no } \\
\text { presente quanto no futuro (TING; LING; CHEAH, 2020). } \\
\text { - Uma crise local de uma empresa global pode tomar grande repercussão } \\
\text { com as redes sociais. As plataformas podem ser grandes aliadas de uma } \\
\text { marca, mas também podem representar ameaças em casos que geram } \\
\text { repercussão negativa para a empresa. Com as mídias sociais, é possível } \\
\text { ocorrer o efeito de transbordamento da crise de um mercado para outros } \\
\text { mercados (SALVADOR; STREHLAU; IKEDA, 2015). }\end{array}$ \\
\hline
\end{tabular}

Avraham (2020); Nixon (2020); Wibowo A., Santoso e Wibowo M. (2020); Prado (2015).

Avraham (2020); Caetano et al. (2020); Ting, Ling e Cheah (2020); Wibowo

A., Santoso e Wibowo M. (2020); Prado (2015); Salvador, Strehlau e Ikeda (2015). 


\section{Gestãoe \\ Desenvolvimento}

\section{Campanhas nas redes sociais / Envolvimento do público}

- Paris iniciou uma campanha com pôsteres impressos e digitais no site da cidade e nas redes sociais Facebook, Twitter e Instagram, ilustrados com fotos da capital e usando hashtags como \#MadeinParis e \#MadeinFrance. Além disso, realizaram uma competição com a hashtag \#ParisWeLoveYou, incentivndo os turistas atuais a compartilhar suas experiências. Bruxelas também solicitou aos turistas que compartilhassem seus momentos com \#visitbrussels (AVRAHAM, 2020).

- Outra campanha foi a 'Ligue para Bruxelas', em que telefones foram colocados pela cidade e potenciais turistas poderiam ligar via Internet e conversar diretamente com os moradores locais, a fim de saber mais sobre a segurança da cidade e verificar se tudo estava em ordem após os ataques terroristas. Além de conversar, também era possivel ver o morador que atendeu a ligação através das câmeras colocadas ao lado dos telefones (AVRAHAM, 2020).

- Chamado de "Jornalismo cidadão", a empresa jornalística MediaNews assumiu a estratégia de se beneficiar do trabalho do público de notícias digitais, no qual seus leitores enviavam novos conteúdos, sendo chamados de 'jornalistas cidadãos'. A MediaNews poderia então usar essas notícias livremente apropriadas como base para explorar a audiência de notícias impressas e digitais (uma estratégia de acumulação de capital típica de empresas de mídia digital como o Google, que capitalizam o conteúdo gerado pelo usuário) (NIXON, 2016 ).

Parceria com famosos na internet

\section{Aplicativos para dispositivos mó- veis}

Após a crise com os ataques terroristas, a França convidou blogueiros e YouTubers de vários países para visitar e conhecer melhor o país (AVRAHAM, 2020).

- A empresa jornalística norte-americana MediaNews passou a explorar a distribuição de notícias através de aplicativos para dispositivos móveis. A empresa desenvolveu um aplicativo chamado "Tapln", que custava US\$ 4,99 por mês e além disso, ainda possuía publicidade. Além deste, uma nova coleção de aplicativos foi criado para cada jornal da MediaNews. Com isso, a empresa jornalística foi classificada como o primeiro jornal digital com reconhecimento de localização do mundo (NIXON, 2020).

- Com o afastamento durante a pandemia do coronavírus, algumas empresas passaram a optar por trabalhar com aplicativos novos e variados em dispositivos móveis que permitissem aos indivíduos uma maior sensação de estar socialmente presentes com a possibilidade de interagir com os demais, tendo grande influência no bem-estar e na produtividade (DWIVEDI et al., 2020).
Avraham (2020); Nixon (2020).

Avraham (2020).

Nixon (2020); Dwivedi et al. (2020); Prado (2015). 


\section{Gestãoe \\ Desenvolvimento}

\section{Publicidade}

Aplicativos e sistemas de rastreamento e monitoramento
- A empresa jornalítica MediaNews fez uso intenso de banners publicitários nos sites de seus jornais e, como é comum na publicidade digital, esses anúncios eram cada vez mais anúncios direcionados. Ela divulgou aos anunciantes a rede de publicidade online que criou em parceria com o Yahoo! com o objetivo de fornecer aos anunciantes os recursos de segmentação online mais avançados disponíveis.

- Além disso, a MediaNews introduziu o Google Consumer Surveys nos sites de seus jornais. Essa ferramente facilita a pesquisa de mercado personalizada. Enquanto o Google cobrava 10 centavos por resposta à pesquisa solicitada pelos anunciantes, a MediaNews colocava as pesquisas em seus sites cobrando 5 centavos dos anunciantes. Além disso, ela passou a negociar com o Google parte do espaço digital em que suas notícias aparecem.

- Em um esforço para alavancar o poder da marca de cada jornal da Media News, uma coleção de aplicativos para tablets e smartphones foi criada. Com isso, foi percebida a possibilidade de contar com a receita de publicidade digital, ofertando publicidade nos aplicativos.

- Durante a pandemia do coronavírus, vários sistemas e aplicativos foram utilizados com o objetivo de monitorar a população. Em Cingapura, o governo utilizou o aplicativo 'Trace Together', que com Bluetooth dos smartphones detecta quando dois dispositivos estiveram em contato próximo. Quando um usuário do aplicativo testava positivo para Covid-19, era solicitado a compartilhar seus dados, alertando outras pessoas que podem ter entrado em contato com esse indivíduo.

- O governo indiano lançou um aplicativo com a mesma funcionalidade, o 'Aarogya Setu'. Além disso, o aplicativo também informava quantos casos positivos Covid-19 eram prováveis em um raio de $500 \mathrm{~m}, 1 \mathrm{~km}, 2 \mathrm{~km}, 5$ $\mathrm{km}$ e $10 \mathrm{~km}$ dos usuários, ajudando as pessoas a entenderem a situação na área.

- Na Índia, também foi projetado um sistema chamado 'TN-ePASS' para compartilhar informações com as autoridades de saúde e administração do distrito sobre todo o movimento de veículos. Ele alertava as autoridades locais sobre a chegada de pessoas de outra região do estado. Assim, eles poderiam tomar as medidas adequadas para a coleta de amostras e quarentena para as chegadas.

- No Reino Unido, o aplicativo de rastreamento de smartphones funcionava da seguinte forma: se e quando uma pessoa fosse diagnosticada com Covid-19, ela precisaria inserir as informações no aplicativo e carregar os 14 dias anteriores para a nuvem. Assim, todos os indivíduos que entraram em contato com o infectado, seriam notificados. Esse aplicativo também pedia para que especificassem seu código postal, ajudando o governo a rastrear o número de infectados em uma área específica e impor medidas de bloqueio em locais com grande número de casos. Além de rastrear, esses aplicativos em muitos casos contribuíram para estudos sobre a doença analisando os sintomas.
Nixon (2020).

Dwivedi et al. (2020). 


\section{Gestãoe \\ Desenvolvimento}

Inovação 'Chamada perdida'

Assinatura digital

Direitos autorais

Aperfeiçoamento da prestação de serviços online
Durante a pandemia da Covid-19, uma inovação indiana simples tornou a comunicação inclusiva e acessível. Funcionava da seguinte maneira: o paciente realizava uma chamada perdida para o número (de modo que não houvesse cobrança) e o sistema retornava realizando perguntas do seu estado de saúde e obtendo as respostas por meio do teclado numérico. Com isso o sistema conseguiu classificar os pacientes entre baixo, médio e alto risco e os que estavam com alto risco, receberiam atendimento domiciliar do departamento de saúde da cidade.

- A empresa jornalística MediaNews optou por um meio tecnológico de controlar o acesso às suas notícias digitais, por meio do chamado 'paywall' nos sites dos seus jornais, extraindo o aluguel dos consumidores. Os leitores teriam acesso a cinco artigos gratuitos por mês. Assim eles só poderiam acessar mais artigos se pagassem por uma assinatura digital. A assinatura funcionava da seguinte maneira: (i) os assinantes atuais da versão impressa poderiam adicionar uma assinatura digital por US\$ 1,99 por mês ou US\$29,99 por ano; (ii) para os que não possuíam uma assinatura impressa, a assinatura apenas digital custaria US\$ 5,99 por mês ou US \$ 59,99 por ano (NIXON, 2020).

- Chamada de "I-News", uma estratégia utilizada durante a crise do jornal impresso pela empresa norte-americana MediaNews foi transferir os custos de produção das notícias para os consumidores, permitindo a impressão do seu próprio jornal digital personalizado (NIXON, 2020).

- Na tentativa de captar os leitores para o meio digital, os assinantes dos jornais impressos do jornal catalão ARA também possuíam acesso a todos os produtos digitais (PRADO, 2015).

As notícias digitais podem ser copiadas facilmente do site de um jornal e reproduzidas em outro site, como por exemplo, um blog. Assim, a MediaNews percebeu a necessidade de assinar um 'Acordo de Aliança de Direitos Autorais', no qual a empresa concordou em ceder seus direitos autorais à empresa contratada para que ela pudesse processar por violação.

A empresa australiana de marketing digital DUK optou por tomar as seguintes medidas: novo software, novo uso de dados, novo mapeamento logístico, novas vendas/segurança de carteira digital, novo gerenciamento de painel, nova qualificação da força de trabalho e nova imagem da marca.
Dwivedi et al. (2020).

Nixon (2020); Prado (2015).

Nixon (2020)

Hamilton (2020) 


\section{Gestãoe \\ Desenvolvimento}

Serviços de saúde

Assistente virtual
Analisando o caso da pandemia do coronavírus:

- Consultas virtuais: consultas operadas por vídeo são realizadas como parte das estratégias nacionais de saúde digital. São duas as possibilidades de uso para a telessaúde: teleconsulta como rastreio para casos graves e teleconsulta para monitoramento de paciente clinicamente estável.

- Teletriagem: esse procedimento classifica os pacientes antes que eles cheguem aos serviços de saúde. Pode colaborar mantendo os assintomáticos ou que apresentam sintomas moderados em casa e encaminhando casos mais graves para os hospitais. Além disso, permite ganhar tempo e evitar sobrecarga nos serviços de saúde. Em alguns locais, como é o caso de Recife, drones equipados com câmeras de infravermelho examinam e identificam indivíduos com temperatura elevada nos pontos de triagem.

- Um assistente virtual foi utilizado durante a pandemia do coronavírus funcionando como um chat médico on-line. Se tratava de um software que simula um ser humano conversando via telefone ou aplicativos de conversa, ajudando a reconhecer sintomas precoces nos pacientes e os encaminhando para tratamento médico em caso de necessidade. Em certas condições, era possivel que um profissional entrasse na conversa e interagisse com o indivíduo, permitindo uma orientação melhor (CAETANO et al., 2020).

- Analisando a crise do imediatismo, Parise, Guinan e Kafka (2016) identificaram dois tipos de especialistas virtuais usados pelas organizações:

Especialista remoto: neste modelo, o especialista está localizado em um ambiente diferente do consumidor e a tecnologia é utilizada para mediar a interação ao vivo entre o consumidor e o especialista no produto. É uma pessoa real localizada remotamente e disponivel para atendimento imediato, oferecendo uma riqueza de imersão ao usuário. $A$ interação pode ocorrer por meio de vídeo em um aplicativo para dispositivo móvel de propriedade do usuário, do atendente da loja ou no site.

Assistente virtual: este modelo utiliza a própria tecnologia na forma de um aplicativo ou plataforma, fornecendo a informações sobre os produtos para o comprador ou para funcionário, geralmente quando ambos estão no mesmo local físico. Além das informações adicionais, também contêm vídeos de demonstração, são comunicadas as chegadas de novos produtos e permite aos usuários comentar, marcar produtos como favoritos' e fazer perguntas.
Caetano et al. (2020).

Caetano et al. (2020); Parise, Guinan e Kafka (2016). 


\section{Gestãoe \\ Desenvolvimento}

\begin{tabular}{|c|c|c|}
\hline $\begin{array}{l}\text { Sistemas de } \\
\text { detecção de pro- } \\
\text { ximidade e de } \\
\text { recomendação de } \\
\text { produto }\end{array}$ & $\begin{array}{l}\text { Quando os serviços de localização são habilitados no telefone do } \\
\text { usuário e um cliente se aproxima de determinado setor da loja, o sis- } \\
\text { tema gera uma recomendação totalmente pessoal para o cliente. } \\
\text { A comunicação com o consumidor é potencializada no lugar certo e na } \\
\text { hora certa com mensagens direcionadas e personalizadas para seus dis- } \\
\text { positivos móveis como, por exemplo, dando boas-vindas na área de entra- } \\
\text { da, enviando ofertas especiais quando passa em determinadas seções da } \\
\text { loja ou avaliações para um produto recém-lançado. As recomendações de } \\
\text { produtos também são baseadas nos dados do histórico de compras das } \\
\text { lojas, a fim de fornecer ao usuário as ofertas mais adequadas e atraentes. } \\
\text { Quando os serviços de localização estão desabilitados, porém conecta- } \\
\text { dos à internet, as ofertas ainda podem ser fornecidas ao consumidor, } \\
\text { mas em um nível mais geral. }\end{array}$ & $\begin{array}{l}\text { Giridhararajan et al. } \\
\text { (2020). }\end{array}$ \\
\hline Discurso & $\begin{array}{l}\text { Pessoas e/ou instituições podem fazer uso de estratégias discursivas no } \\
\text { meio digital, utilizando o discurso como sua estratégia para atingir seus } \\
\text { objetivos. Durante a crise dos refugiados de } 2015 \text {, políticos nacionalistas } \\
\text { da Finlândia e Suécia utilizaram estratégias discursivas com elementos } \\
\text { verbais e visuais em suas redes sociais com o intuito de parecer racionais } \\
\text { e imparciais, persuadir os seguidores e adquirir maior apoio à sua opinião } \\
\text { contrária à imigração, com o discurso de nação sob ameaça. }\end{array}$ & Pettersson e Sakki (2017). \\
\hline $\begin{array}{l}\text { G20 na governança } \\
\text { da economia digital }\end{array}$ & $\begin{array}{l}\text { 2015: Na Cúpula de Antalya, as questões da economia digital estiveram } \\
\text { em } 1^{\circ} \text { lugar na agenda do G20. Nela, os líderes do G20 reconheceram que } \\
\text { estamos na era da economia da internet e que isso traz oportunidades e } \\
\text { desafios, principalmente no assunto segurança, para o crescimento glo- } \\
\text { bal. } \\
\text { 2016: Na Cúpula do G20 em Hangzhou, houve uma discussão dos papéis } \\
\text { que a economia digital desempenhou na inovação e no crescimento eco- } \\
\text { nômico. Esta Cúpula lançou a 'Iniciativa de Cooperação e Desenvolvimen- } \\
\text { to da Economia Digital', formando uma estratégia que acelera a economia } \\
\text { digital e o crescimento inclusivo. } \\
\text { 2017: Na Cúpula do G20 em Hamburgo, os líderes garantiram que até } \\
2025 \text { todos os seus cidadãos estarão conectados digitalmente. Os se- } \\
\text { guintes princípios para o estímulo ao crescimento econômico digital fi- } \\
\text { caram acordados: } \\
\text { (a) Inovação: crucial para o crescimento econômico inclusivo; } \\
\text { (b) Parceria: uma parceria mais estreita entre os membros do G20, com } \\
\text { partilha dos conhecimentos e experiências para uma maior cooperação, } \\
\text { principalmente entre países tecnologicamente avançados e outros que } \\
\text { ainda não são; e } \\
\text { (c) Inclusão: um ambiente de negócios aberto e inclusivo facilitará o cres- } \\
\text { cimento econômico, criará confiança mútua e salvaguardará o fluxo de } \\
\text { informações. A inclusão também é em relação a combater a exclusão di- } \\
\text { gital de gênero e envolver as mulheres na economia digital. }\end{array}$ & $\begin{array}{l}\text { Guo, Ding e Lanshina } \\
\text { (2017). }\end{array}$ \\
\hline
\end{tabular}

\section{Fonte: Elaborado pelos autores.}




\section{Gestãoe \\ Desenvolvimento}

e-ISSN: 2446-6875

p-ISSN: $1807-5436$

\subsection{FRAMEWORK DA PESQUISA}

Um framework de pesquisa foi criado com o objetivo de sintetizar as descobertas desta revisão integrativa, conforme pode ser visto na Figura 1.

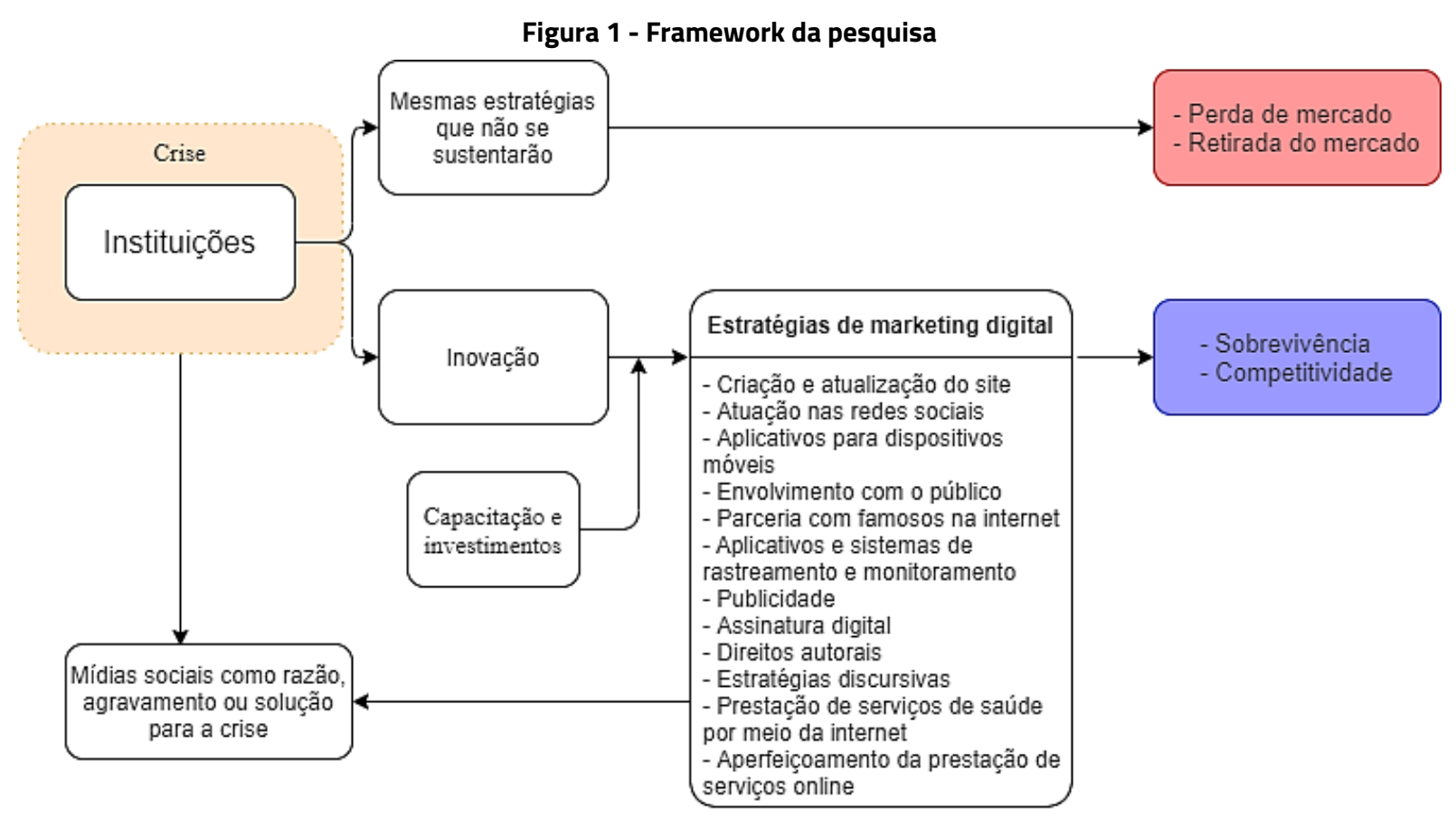

Fonte: Elaborado pelos autores

Esta revisão integrativa analisa organizações que passaram ou estão passando por algum tipo de crise. Após o estudo, pode-se perceber que se tem dois caminhos: (i) continuar na zona de conforto com as mesmas estratégias adotadas há anos, mesmo sabendo que elas não se sustentarão por muito tempo, podendo leva a uma perda de mercado ou até mesmo à falência da organização ou (ii) optar pela inovação, aderindo a estratégias de marketing digital, na busca de sobreviver e continuar no mercado competitivo. Muitas estratégias foram encontradas nesta pesquisa, como pode ser visto na Figura 1. Dois caminhos são apresentados. Porém, a opção "optar pela inovação" não é algo tão fácil que pode ser feito repentinamente pelas organizações. Na maioria das vezes, são necessários investimentos e capacitação dos membros para que sejam realizadas estratégias digitais efetivas, que gerarão o resultado esperado.

Uma observação é colocada no framework. As mídias sociais podem funcionar como boas soluções para controlar ou dominar diversas crises, sendo uma estratégia de marketing social eficiente. Porém, elas também podem agravar ou até mesmo ser a causa de crises de uma marca ao possibilitar o debate e a repercussão de um tema e também por não ser utilizada da melhor maneira. Uma polêmica pode atingir 
uma extensão muito maior através das redes sociais. Esse é um dos motivos pelas quais é necessário apostar em capacitação e investimentos ao optar por utilizar estratégias digitais. É necessário entender a esfera da internet, suas oportunidades e os desafios que nela contém.

\section{CONCLUSÃO}

Esta pesquisa teve como objetivo analisar quais são as estratégias de marketing digital adotadas por organizações em diferentes situações de crise. Por meio de uma revisão integrativa de artigos que envolviam a temática, foi possível listar diversas estratégias no meio digital capazes de colaborar com os desafios que as organizações enfrentam com a globalização, como investir nos seus sites, atuar nas suas mídias sociais com conteúdo e campanhas, aplicativos, assistentes virtuais, publicidade e outros. Cada vez mais as organizações estão investindo no meio digital, fornecendo um serviço instantâneo ao consumidor. Em um mundo competitivo como o atual, ganhar vantagem diferencial em uma entrega rica de experiência ao cliente no espaço digital é algo que não pode ser mais deixado para depois.

Como contribuições tanto teóricas quanto gerenciais, esse artigo traz uma discussão sobre diversas estratégias de marketing digital que foram aderidas pelas empresas em crise fruto de diferentes situações. A intenção dos autores é que esta discussão colabore com os debates que ocorrem nas disciplinas de marketing e gestão. Além disso, organizações, mesmo que de outros setores dos citados, podem se espelhar nessas estratégias de modo a vencer a crise que enfrentam ou até mesmo aderi-las para que não sejam atingidas por adversidades inesperadas, resultando em perda de espaço ou até mesmo em sua retirada do mercado. $\mathrm{O}$ framework foi criado de modo a sintetizar as descobertas e colaborar com os leitores, trazendo-as de forma mais compreensivel, não sendo acessivel somente para pesquisadores devido ao vocabulário dos artigos escritos na área acadêmica.

As limitações do estudo envolvem analisar estratégias de marketing digital em situações de crise de uma maneira geral. Assim, sugere-se que sejam analisadas situações específicas, por exemplo, pandemias. Além disso, sugere-se um estudo que analise com maior profundidade as estratégias realizadas nas redes sociais e nos aplicativos das empresas.

\section{REFERÊNCIAS}

AVRAHAM, E. Combating tourism crisis following terror attacks: image repair strategies for European destinations since 2014. Current Issues in Tourism, p. 1-14, 2020. 
BEHERA, R. K.; GUNASEKARAN, A.; GUPTA, S.; KAMBOJ, S.; BALA, P. K. Personalized digital marketing recommender engine. Journal of Retailing and Consumer Services, v. 53, p. 1-24, 2020.

BUSCA, L.; BERTRANDIAS, L. A framework for Digital Marketing Research: investigating the four cultural eras of Digital Marketing. Journal of Interactive Marketing, v. 49, p. 1-19, 2020.

CAETANO, R. et al. Desafios e oportunidades para telessaúde em tempos da pandemia pela Covid-19: uma reflexão sobre os espaços e iniciativas no contexto brasileiro. Cad. Saúde Pública, v. 36, n. 5, p. $1-16,2020$.

CARNIELLO, M. F.; SANTOS, M. J.; OLIVEIRA, E. A. A. Q. Uso de ferramentas de comunicação digital na gestão de municípios das capitais brasileiras. Revista Gestão e Desenvolvimento, v. 8, n. 1, p. 9-21, 2011.

CARPIO, K. V. H.; ARCE, S.; ENJOLRAS, M.; CAMARGO, M. How Institutions Promote Digital Marketing in Small and Medium International Companies: a Comparison Between Costa Rica and France. Technology Innovation Management Review, v. 10, n. 4, 2020.

COOPER, H. M. Organizing knowledge syntheses: A taxonomy of literature reviews. Knowledge in Society, v. 1, p. 104-126, 1988.

COREYNEN, W.; MATTHYSSENS, P.; VAN BOCKHAVEN, W. Boosting servitization through digitization: pathways and dynamic resource configurations for manufacturers. Industrial Marketing Management, v. 60, p. 42-53, 2017.

DWIVEDI, Y. K. et al. Impact of Covid-19 pandemic on information management research and practice: Transforming education, work and life. International Journal of Information Management, 2020.

FIERRO, I.; ARBELAEZ, D. A. C.; GAVILANEZ, J. Digital marketing: a new tool for international education. Pensamiento y Gestión, v. 43, p. 240-260, 2017.

GIRIDHARARAJAN, R.; VASUDEVAN, S. K.; THANGAVELU, S.; SINI RAJ, P. IOT Based Approach for the Increased and Improved sales for the Brick and Mortar Stores. International Journal of Advanced Trends in Computer Science and Engineering, v. 9, n. 3, p. 3048-3052, 2020.

GUO S.; DING W.; LANSHINA T. Global Governance and the Role of the G20 in the Emerging Digital Economy. International Organisations Research Journal, v. 12, n. 4, p. 169-184, 2017.

HAMILTON, J. The Strategic Change Matrix and Business Sustainability across Covid-19. Sustainability, v. 12, n. 15, 2020. 
KANNAN, P. K.; LI, H. A. Digital marketing: A framework, review and research agenda. International Journal of Research in Marketing, v. 34, n. 1, p. 22-45, 2017.

LOUW, C.; NIEUWENHUIZEN, C. Digitalization strategies for SMEs: A cost vs. skill approach for website development. African Journal of Science, Technology, Innovation and Development, p. 1-8, 2019.

MACHADO, Jones. Estratégias comunicacionais no contexto de crise: os contratos de comunicação da Petrobras, 0 Globo e Planalto em mídias digitais. 2015. 151f. Tese (Doutorado em Comunicação) Centro de Ciências Sociais e Humanas, Universidade Federal de Santa Maria, Santa Maria, Tio Grande do Sul, 2016.

MACHADO, Jones; BARICHELLO, Eugenia M. Mariano da Rocha. Comunicação de crise em mídias sociais digitais: um estudo do Twitter, do Facebook e do blog corporativo da Petrobras. Organicom, v. 12, n. 22, p. 187-197, 2015.

MACHADO, Jones; DURANTE, Juliana Baggattini; VIEGAS JUNIOR, Sérgio Tadeu Fraga. Relações públicas digitais: estratégias organizacionais na comunicação da crise. Rev. Cad. Comun., v. 23, n. 1, p. 1-20, 2019.

MARÍN LÓPEZ, J. C.; LÓPEZ TRUJILLO, M. Análisis de datos para el marketing digital emprendedor: Caso de estudio del Parque de Innovación Empresarial de Manizales. Universidad \& Empresa, v. 22, n. 38, p. $65-78,2020$.

MARTÍNEZ-LÓPEZ, F. J.; ANAYA-SÁNCHEZ, R.; AGUILAR-ILLESCAS, R.; MOLINILLO, S. Online Brand Communities: Using the Social Web for Branding and Marketing. Berlín: Springer, 2015.

MATEI, A. I.; SAVULESCU, C. Towards Sustainable Economy through Information and Communication Technologies Development: Case of the EU. Journal of Security and Sustainability Issues, v. 2, n. 2, p. $5-17,2012$

MONTARDO, S. P.; ROSA, P. M. Blog Corporativo como Ferramenta de Marketing de Relacionamento: Estudo de Caso na Região Metropolitana de Porto Alegre e no Vale do Sinos. Gestão e Desenvolvimento, v. 5, n. 2, p. 87-94, 2008.

NIXON, B. The business of news in the attention economy: Audience labor and MediaNews Group's efforts to capitalize on news consumption. Journalism, v. 21, n. 1, p. 73-94, 2020.

PARISE, S.; GUINAN, P. J.; KAFKA R. Solving the crisis of immediacy: How digital technology can transform the customer experience. Business Horizons, v. 59, n. 4, p. 411-420, 2016. 
PÉREZ-FABARA, M. A.; CHARRO, R. S. Motivación y esferas del consumidor digital. Journal Publicando, v. 12, n. 2, p. 269-282, 2017.

PETTERSSON, K.; SAKKI, I. Pray for the fatherland! Discursive and digital strategies at play in nationalist political blogging. Qualitative Research in Psychology, v. 14, n. 3, p. 315-349, 2017.

PRADO, E. The press in Catalonia: between the digital challenge and nation building. Media, Culture \& Society, v. 37, n. 1, p. 134-143, 2015.

SALVADOR, A. B.; STREHLAU, V. I.; IKEDA, A. A. Crise Local de Marca Global e o Uso de Monitoramento de Redes Sociais. Revista Brasileira de Marketing, v. 14, n. 4, p. 438-450, 2015.

SAURA, J. R.; PALOS-SANCHEZ, P.; HERRÁEZ, B. R. Digital Marketing for Sustainable Growth: BusinesS Models and Online Campaigns Using Sustainable Strategies. Sustainability, v. 12, n. 3, 2020.

TING, H.; LING, J.; CHEAH, J. H. Editorial: It Will Go Away!? Pandemic Crisis and Business in Asia. Asian Journal of Business Research, v. 10, n. 1, p. 1-7, 2020.

TORRACO, R. J. Writing integrative literature reviews: Using the past and present to explore the future. Human Resource Development Review, v. 15, n. 4, p. 404-428, 2016.

WANG, F. Digital marketing capabilities in international firms: a relational perspective. International Marketing Review, v. 37, n. 3, p. 559-577, 2020.

WIBOWO, A.; SANTOSO, J. T.; WIBOWO, M. C. Adoption of Technopreneurship and Information Technology in Accelerating the Growth of Digital-Based Entrepreneurs. Test Engineering and Management, v. 83, p. 18091-18095, 2020.

WORLD BANK. World Development Report 2016: Digital Dividends, World Bank Group, Washington, DC. 2016. https://www.worldbank.org/en/publication/wdr2016 